\title{
Exploration of Hepatoprotective Effect of Gentiopicroside on Alpha- Naphthylisothiocyanate-Induced Cholestatic Liver Injury in Rats by Comprehensive Proteomic and Metabolomic Signatures
}

\author{
Han Han ${ }^{a, b, c}$ Lili Xu ${ }^{b}$ Kai Xiong ${ }^{c}$ Tong Zhanga ${ }^{a, c}$ Zhengtao Wang ${ }^{b}$
}

aExperiment Center for Teaching and Learning, Shanghai University of Traditional Chinese Medicine, Shanghai, 'Institute of Chinese Materia Medica, Shanghai University of Traditional Chinese Medicine, Shanghai, 'School of Pharmacy, Shanghai University of Traditional Chinese Medicine, Shanghai, China

\section{Key Words}

Gentiopicroside • ANIT-induced cholestasis • Proteomics • Metabolomics

\begin{abstract}
Background/Aims: Cholestasis is the major cause of the accumulation of bile acids and results in liver damage, fibrosis, and failure. A growing number of studies have shown that gentiopicroside is a promising prospect that may protect the liver. However, its therapeutic mechanism has not yet been clarified. This study aimed to explore the effect and mechanism of gentiopicroside in cholestasis induced by alpha-naphthylisothiocyanate. Methods: We performed isobaric tags for relative and absolute quantification-based quantitative proteomics and metabolomics using liquid chromatography quadruple time-of-flight mass spectrometry and identified the expression of 73 metabolites and 84 proteins associated with cholestasisrelated dysfunctions in the metabolism of bile acids, fatty acids, and glycerophospholipids. Results: Integrated analyses of proteomic and metabonomic studies showed altered pathways in cholestasis-induced liver injury involving increased activity of farnesoid $X$ receptor/retinoid $X$ receptor, bile acid biosynthesis, and peroxisome proliferator-activated receptor- $\alpha /$ retinoid $X$ receptor- $\alpha$. Gentiopicroside could reverse these metabolite, protein, and blood biochemical indices, as well as alleviate liver damage. The progressive changes in the proteins and genes may be correlated with cholestasis and were confirmed by western blot and quantitative realtime polymerase chain reaction. Conclusion: Gentiopicroside could be used to protect the liver in the presence of cholestasis.




\section{Cellular Physiology Cell Physiol Biochem 2018;49:1304-1319 and BiOChemistry \begin{tabular}{l|l} 
DOI: 10.1159/000493409 & Published online: 12 September, 2018 \\
(c) 2018 The Author(s). Published by S. Karger AG, Basel \\
wwwarger.com/cpb
\end{tabular} Tong et al.: Omic Study of the Effect of Gentiopicroside on Cholestasis}

\section{Introduction}

Bile formation is a vital function of the liver in all vertebrates. Bile acids (BAs) are the major constituents of bile. They stimulate bile secretion and are required for intestinal absorption of lipids and fat-soluble vitamins. BAs also modulate gene expression through signal transduction pathways that regulate lipid metabolism and energy expenditure [1]. However, disruption of BA excretion results in BA accumulation in the liver, which can result in hepatotoxicity and even lead to cirrhosis and hepatic necrosis [2, 3]. Despite this wellknown sequence of events, the molecular mechanisms by which BAs injure the liver remain unclear. Additionally, there are few treatments available for cholestasis. One hypothesis is that toxic BAs induce hepatocyte apoptosis by activating death receptors [4]. This hypothesis was based primarily on in vitro observations from cultured cells exposed to high concentrations of toxic BAs $[5,6]$. However, such high concentrations are rarely observed in sera from cholestatic patients and animal models [7, 8]. Most importantly, hepatocyte apoptosis has not been detected in vivo in the livers of bile duct ligated mice or in vitro in BA-treated human hepatocytes $[9,10]$, which suggests that BA-induced liver injury occurs by alternative mechanisms.

Ursodeoxycholic acid (UDCA) is the only drug currently available to treat cholestasis that has been approved by the US Food and Drug Administration. However, the efficacy of UDCA is inconsistent, and it has no effect on some patients with cholestasis [11]. Therefore, new therapies are urgently needed because of the limitations of this drug [12]. Gentiopicroside (GPS), which is an active compound isolated from the plant Gentiana rigescens Franch.ex Hemsl, has been used for the treatment of jaundice and other hepatobiliary diseases in China [13]. Several studies have shown that GPS has protective effects on the hepatobiliary system [13-15]. In recent years, the mechanisms of chemicals and Chinese herbal medicines in liver diseases [16-20] such as liver fibrosis [21-23] have been investigated. In addition, metabolomics has also been used to study the mechanisms of disease by detecting small metabolites produced by normal or pathological cellular processes [24]. Several serum metabolites have been identified as novel biomarkers of cholestasis induced by alphanaphthylisothiocyanate (ANIT) [25]. However, proteomics and metabolomics have not been simultaneously used to study ANIT-induced cholestasis. ANIT is a model hepatotoxin for cholestatic hepatitis, which can cause cessation of bile flow in vivo, hepatic parenchymal cell damage, and infiltration of neutrophils around bile ducts [11].

In the present study, based on ANIT-induced cholestasis, we explored the anti-cholestatic effect of GPS via a proteomics profile of the liver and untargeted metabolic profiling of the liver, serum and urine based on liquid chromatography (LC)-mass spectroscopy (MS). The results showed that a series of differentially expressed proteins (DEPs) and metabolites were altered during the development of liver injury. These molecules are primarily involved in the metabolism of BAs, fatty acids (FAs), and lipids. Thus, we suggested a potential novel sequential mechanism to explain the initiation of BA-induced liver injury in cholestasis and highlight the potential therapeutic effects of GPS for cholestatic hepatitis.

\section{Materials and Methods}

\section{Materials and instruments}

ANIT was purchased from Sigma-Aldrich (St. Louis, MO). Formic acid, methanol, and ACN (MS-grade) were purchased from Merck Serono Co., Ltd. (Beijing, China). GPS was purchased from Shanghai Yuanye Biotechnology Co., Ltd. (Shanghai, China) and identified by nuclear magnetic resonance and mass spectral data according to the literature. The purity of GPS was more than $98 \%$ as confirmed by high-performance liquid chromatography analysis. Ultrapure water was produced by Milli-Q system (Millipore, Bedfordshire, UK). Other chemicals were purchased from Shanghai Chemical Factory (Shanghai, China).

\section{Animals}

Male Sprague-Dawley rats (200-220 g) were obtained from the laboratory animal center of the Shanghai University of Traditional Chinese Medicine (SHUTCM; Shanghai, China). All animal maintenance and treatment protocols were in accordance with local institutional guidelines for the care and use of laboratory animals approved by the Institutional Animal Committee of SHUTCM (approval file no. 


\section{Cellular Physiology Cell Physiol Biochem 2018;49:1304-1319 \\ \begin{tabular}{l|l|l} 
and Biochemistry $10.1159 / 000493409$ & $\begin{array}{l}\text { C) } 2018 \text { The Author(s). Published by S. Karger AG, Basel } \\
\text { www.karger.com/cpb }\end{array}$ \\
\hline
\end{tabular}}

Tong et al.: Omic Study of the Effect of Gentiopicroside on Cholestasis

SZY201611003). Rats were randomly divided into the following six groups: control ( $\mathrm{n}=12)$; ANIT (60 mg/ $\mathrm{kg}$ dissolved in olive oil, $\mathrm{n}=12$ ); ANIT-GPS low-dose treatment group (L-GPS; $80 \mathrm{mg} / \mathrm{kg}, \mathrm{n}=12$ ); ANIT-GPS moderate-dose treatment group (M-GPS; $120 \mathrm{mg} / \mathrm{kg}, \mathrm{n}=12$ ); ANIT-GPS high-dose treatment group (H-GPS; $150 \mathrm{~kg} / \mathrm{kg}, \mathrm{n}=12$ ); and UDCA (70 mg/kg, $\mathrm{n}=12$ ). The control group was administered intragastric olive oil. The GPS and UDCA groups were administered GPS $(80,120$, and $150 \mathrm{mg} / \mathrm{kg})$ and UDCA, respectively, for 5 days and ANIT ( $60 \mathrm{mg} / \mathrm{kg}$, dissolved in olive oil) was administered on day 3. On day 5 , all rats were placed individually in metabolic cages and urine was collected for $24 \mathrm{~h}$. The rats were sacrificed on day 6. Blood was immediately collected from the postcava and centrifuged at $3500 \mathrm{rpm}$ for $5 \mathrm{~min}$ at $4{ }^{\circ} \mathrm{C}$. Urine was centrifuged at $3500 \mathrm{rpm}$ for $5 \mathrm{~min}$ at $4{ }^{\circ} \mathrm{C}$ to obtain the supernatants. The livers were removed after the rats were euthanized. The livers were fixed in $10 \%$ neutral buffered formalin, embedded in paraffin, and stained with hematoxylin and eosin (H\&E) for pathological examination. Other liver samples were stored in liquid nitrogen for proteomic, metabolomic, real-time PCR, and western blot analyses. The urine and serum samples were stored at $-80^{\circ} \mathrm{C}$.

\section{Biochemical assay and histological study}

Aspartate aminotransferase (AST), alanine aminotransferase (ALT), alkaline phosphates (ALP), total bilirubin (TBIL), direct bilirubin (DBIL), and intrahepatic total bile acids (TBA) were assessed by commercial kits (Sigma-Aldrich). Livers were fixed in 10\% neutral buffered formalin, embedded in paraffin, and stained with H\&E for further histological analysis.

\section{Sample processing and detection for metabolomics}

Each serum sample $(100 \mu \mathrm{L})$ was added to $300 \mu \mathrm{L}$ of methanol (containing $100 \mu \mathrm{g} / \mathrm{mL}$ of L-2chlorophenylalanine), vortexed for $2 \mathrm{~min}$, and then centrifuged at $12,000 \mathrm{rpm}$ for $10 \mathrm{~min}$ at $4{ }^{\circ} \mathrm{C}$. The supernatant was transferred into a sample vial after being filtered through a $0.2-\mu \mathrm{m}$ membrane. |Urine samples were centrifuged at $13,000 \mathrm{rpm}$ for $10 \mathrm{~min}$ at $4{ }^{\circ} \mathrm{C}$. Supernatants $(400 \mu \mathrm{L})$ were added to ultrapure water $(400 \mu \mathrm{L})$, vortexed for $2 \mathrm{~min}$, and filtered through a $0.2-\mu \mathrm{m}$ membrane. Liver tissue $(50 \mathrm{mg})$ was added to $500 \mu \mathrm{L}$ of methanol and homogenized. Liver homogenates were settled for $10 \mathrm{~min}$ at $-20^{\circ} \mathrm{C}$ and then centrifuged at $12,000 \mathrm{rpm}$ for $10 \mathrm{~min}$ at $4{ }^{\circ} \mathrm{C}$. Supernatants were directly transferred into sample vials.

Aliquots $(2 \mu \mathrm{L})$ of each sample were injected into a BEH C18 column $(1.7 \mu \mathrm{m}, 100 \mathrm{~mm} \times 2.1 \mathrm{~mm})$ with a column temperature of $45^{\circ} \mathrm{C}$ and an ultra-performance LC-coupled SynaptG2-Si quadrupole time-of-flight MS system (Waters, Milford, MA). The flow rate was $350 \mu \mathrm{L} / \mathrm{min}$, and the mobile phase was composed of phase A (ultrapure water with $0.1 \%$ formic acid) and phase $\mathrm{B}$ (ACN, $0.1 \%$ formic acid). The gradient elution procedure was as follows: 0-2 $\mathrm{min}, 5 \% \mathrm{~B} ; 2-13 \mathrm{~min}, 5-95 \% \mathrm{~B} ; 13-15 \mathrm{~min}, 95 \% \mathrm{~B}$; and post time (3 min). Data were acquired in positive and negative ion modes. MS parameters were as follows: capillary voltages of $3.2 \mathrm{kV}$ in positive mode and $3 \mathrm{kV}$ in negative mode; cone gas flow, $60 \mathrm{~L} / \mathrm{h}$; gas temperature, $300^{\circ} \mathrm{C}$; nebulizer pressure, 45 psig; cone voltages of $35 \mathrm{~V}$ for positive- and $50 \mathrm{~V}$ for negative-ion mode; scan range, 50-1000 $\mathrm{m} / \mathrm{z}$.

\section{Experimental design and statistical rationale}

Raw data were processed using MarkerLynx Applications Manager Version 4.1 (Waters, Manchester, UK) for normalization, alignment, peak filtering, and statistical analysis. A list containing the retention times, mass to charge ratios, sample names, and ion intensities was generated, and the dataset was imported into SIMCA-P 13.0 software (Umetrics, Umeå, Sweden) for principal component analysis (PCA) and partial-leastsquares discriminate analysis (PLS-DA) to visualize the metabolic alterations among the ANIT, GPS, and control groups. To guard against overfitting of the PLS-DA model, a 7-round cross-validation was performed with $1 / 7$ th of the samples excluded from the mathematical model in each round. Potential biomarkers were selected according to the variable importance in the projection (VIP) values, and metabolites with VIP > 1 were considered potential differentially expressed metabolites. Student's t-tests were used to determine whether the differential metabolites obtained from PLS-DA modeling were significantly different $(\mathrm{p}<0.05)$ among the ANIT, GPS, and control groups. Finally, only the metabolites with VIP $>1$ and $p<0.05$ were selected as the potential biomarkers. We used the Kyoto Encyclopedia of Genes and Genomes (KEGG; http:// www.genome.jp) and Human Metabolome Database (http://www.hmdb.ca) to identify potential markers by comparing the precise molecular weight and the fragment ion mass detected by tandem MS (MS/MS). Furthermore, the structures of biomarkers were validated by comparing the samples with commercially available standard compounds.

\section{Proteomics: protein extraction}

Liver tissue samples from the control, ANIT, M-GPS, and UCDA groups were ground into powders using liquid nitrogen. Lysis solution and a protease inhibitor were added to each $0.1 \mathrm{~g}$ of powder. The samples 


\section{Cellular Physiology Cell Physiol Biochem 2018;49:1304-1319 \\ \begin{tabular}{l|l|l} 
and Biochemistry $10.1159 / 000493409$ & $\begin{array}{l}\text { C } 2018 \text { The Author(s). Published by S. Karger AG, Basel } \\
\text { www.karger.com/cpb }\end{array}$ \\
\hline
\end{tabular}}

Tong et al.: Omic Study of the Effect of Gentiopicroside on Cholestasis

were ultrasonicated at $4{ }^{\circ} \mathrm{C}$ for $3 \mathrm{~min}(80 \mathrm{~W}$, on for $0.8 \mathrm{~s}$ and off for $0.8 \mathrm{~s})$ and centrifuged at $12,000 \mathrm{rpm}$ at 4 ${ }^{\circ} \mathrm{C}$ for $10 \mathrm{~min}$. Supernatants were collected, and cooled acetone was added. The solution was centrifuged at $12,000 \mathrm{rpm}$ for $10 \mathrm{~min}$ at $4{ }^{\circ} \mathrm{C}$. The precipitates were collected, and cooled acetone was added. The solutions were centrifuged at $12,000 \mathrm{rpm}$ for $15 \mathrm{~min}$ at $4{ }^{\circ} \mathrm{C}$, and the isolates collected. This step was performed twice. The isolates were dissolved in lysis solution. The solution was centrifuged at 12, $000 \mathrm{rpm}$ for 15 min at $25^{\circ} \mathrm{C}$. Supernatants were again collected and centrifuged. The concentrations of the proteins in the supernatants were detected by the bicinchoninic acid method.

\section{Preparation of protein samples}

Proteins $(100 \mu \mathrm{g})$ were obtained from each pooled sample, and cold acetone with four-fold volumes of the proteins was added at $-20^{\circ} \mathrm{C}$ and incubated for $1 \mathrm{~h}$. The solutions were centrifuged at $12,000 \mathrm{rpm}$ for $15 \mathrm{~min}$ at $4{ }^{\circ} \mathrm{C}$. The precipitates were collected and freeze-dried. After $50 \mu \mathrm{L}$ of the dissolution buffer and 4 $\mu \mathrm{L}$ of the reducing reagent were added, the samples were incubated at $60^{\circ} \mathrm{C}$ for $1 \mathrm{~h}$. Then, $2 \mu \mathrm{L}$ of cysteineblocking reagents were added at $25^{\circ} \mathrm{C}$ for $10 \mathrm{~min}$. The solutions were centrifuged at $12,000 \mathrm{rpm}$ for 20 min to clean the protein solution. After adding $100 \mu \mathrm{L}$ of dissolution buffer, the solutions were centrifuged at 12, $000 \mathrm{rpm}$ for $1 \mathrm{~min}$. This step was repeated three times. The solutions were transferred to new tubes, and $50 \mu \mathrm{L}$ of sequencing-grade trypsin $(50 \mathrm{ng} / \mu \mathrm{L})$ was added and tubes were incubated at $37^{\circ} \mathrm{C}$ for $12 \mathrm{~h}$. Solutions were centrifuged at 12,000 rpm for $20 \mathrm{~min}$, and the peptides were collected. The filter units were transferred to new tubes, and dissolution buffers $(50 \mu \mathrm{L})$ were again added to the tubes.

\section{Protein labeling and MS analysis}

The 8-plex iTRAQ Reagent Multiplex Kit protocol (Applied Biosystems, Foster City, CA) was used for differential labeling. The control, ANIT, M-GPS, and UCDA groups were labeled as follows: 113, 114; 115, 116; 117, 118; and 119, 121. Pooled samples were mixed and dried. The dried sample was resuspended with $100 \mu \mathrm{L}$ of buffer A (20 mM ammonium formate, water, $\mathrm{pH} 10$ ). Fractionation was performed using the Ultramex SCX column $(4.6 \mathrm{~mm} \times 250 \mathrm{~mm})$ with UV detection at $215 \mathrm{~nm}$ and $280 \mathrm{~nm}$. Separation was performed as follows: 0-5 min, 5\% B (20\% 20 mM ammonium formate, 80\% ACN, pH 10); 5-30 min, 5-15\% B; 30-45 min, 15-38\% B; 45-46 min, 38-90\%; 46-54.5 min, 90\% B; 54.5-55 min, 90-5\% B; and 55-65 min, $5 \%$ B. The flow rate was $0.8 \mathrm{~mL} / \mathrm{min}$. Each segment was collected at intervals of $1 \mathrm{~min}$ for the 8-65 min, and five tubes were mixed to give a total of 10 segments. All segments were dried in a vacuum freeze dryer for further LC-MS/MS analysis.

\section{Reversed-phase LC-MS/MS analysis}

Dried samples were resuspended with $60 \mu \mathrm{L}$ of $2 \%$ ACN and $0.1 \%$ formic acid. Separation was performed on the Eksigent NanoLC-Ultra ${ }^{\mathrm{TM}}$ system with NanoLC trap ChromXP C18 $(350 \mu \mathrm{m} \times 0.5 \mathrm{~mm}, 3$ $\mu \mathrm{m}, 120 \mathrm{~A})$ and washed with buffer A $(0.1 \%$ formic acid, water) and buffer B $(98 \% \mathrm{ACN}, 2 \%$ water, $0.1 \%$ formic acid) at $3 \mu \mathrm{L} / \mathrm{min}$. The 90 -min gradient was $0-0.1 \mathrm{~min}, 5-10 \% \mathrm{~B} ; 0.1-60 \mathrm{~min}, 10-28 \% \mathrm{~B} ; 60-75$ min, 28-50\% B; 75-75.5 min, 50-80\% B; 75.5-80 min, 80\% B; 80-80.5 min, 80-5\% B; 80.5-90 min, 5\% B. Data were acquired by AB SCIEX TripleTOF 5600 with an ion spray voltage of $2.5 \mathrm{kV}$, curtain gas of 30 psi, nebulizer gas of $5 \mathrm{psi}$, and an interface heater temperature of $150^{\circ} \mathrm{C}$. A full-scan MS experiment (scan range $800-4000 \mathrm{~m} / \mathrm{z}$ ) was performed, followed by MS/MS on the top 30 ions detected. The MS/MS scan range was $100-1800 \mathrm{~m} / \mathrm{z}$ at a resolution of 20,000 and the scan time was $100 \mathrm{~ms}$.

\section{Protein identification, quantification, and pathway analysis}

Protein Pilot Software v. 5.0 (AB Sciex, Foster City, CA) was used for peak analysis and data processing with the Uniprot rat database (http://www.uniprot.org/). The fold changes among proteins in different groups were calculated as average values from the protein isobaric tags for relative and absolute quantification ratios. The P value was calculated using the Student's t-test via SPSS 19.0. P $<0.05$ and a fold change of more than 1.3 or less than 0.77 were considered statistically significant. Differentially expressed DEP classification was based on functional annotations using Gene Ontology (GO) analysis for molecular functions, biological processes, and cellular components.

\section{Pathway analysis and interactive network construction by Ingenuity Pathway Analysis software}

For pathway and network analyses, the differentially expressed metabolites and DEPs (with KEGG IDs, UniProt IDs) and their fold change directions were encoded into the Ingenuity Pathways Analysis (IPA) software (Ingenuity Systems, Mountain View, CA). This software is web-based and suggests possible biochemical, molecular, and biological functions of the input metabolites and proteins. The molecular interaction networks among the proteins and metabolites were constructed based on the database of IPA. 


\section{Cellular Physiology Cell Physiol Biochem 2018;49:1304-1319 and BiOChemistry \begin{tabular}{l|l} 
DOI: 10.1159/000493409 & $\begin{array}{l}\text { Published online: 12 September, } 2018 \\
\text { www.karger.com/cpb }\end{array}$
\end{tabular} Tong et al.: Omic Study of the Effect of Gentiopicroside on Cholestasis}

Quantitative real-time PCR analysis

Total RNA in liver samples was extracted by an RNA extraction kit according to the manufacturer's protocol (Takara Bio, Inc., Kusatsu, Japan). Reverse transcription and quantitative real-time PCR (qRTPCR) were performed to evaluate the expression of ALDH1L1, ABCB4, ABCB11, MRP4, CYP2A12, CYP7A1, and farnesoid $\mathrm{X}$ receptor (FXR). Total RNA $(1 \mu \mathrm{g})$ was reverse-transcribed to the first-strand cDNA by Prime Script TMRT Master Mix (Takara Bio, Inc.), and then the expression levels of mRNA were quantified by real-time PCR using SYBR premix Ex TaqTM (Takara Bio, Inc.). The PCR program included 1 cycle at $95^{\circ} \mathrm{C}$ for $30 \mathrm{~s}, 40$ cycles at $95^{\circ} \mathrm{C}$ for $5 \mathrm{~s}$, and $60{ }^{\circ} \mathrm{C}$ for $30 \mathrm{~s}$. The results were expressed by calculating the $2-\Delta \Delta$ CT values. Data were normalized with GAPDH for variance. The PCR primer pairs of all genes are shown in Table 1.

\section{Western blot}

Antibodies against STAT3 and NQ01 (Sigma-Aldrich) were used for western blot analysis. The liver samples were lysed using RIPA (Beyotime, Shanghai, China), and the protein concentration was determined by a Bradford kit (Beyotime). Protein $(30 \mu \mathrm{g}$ ) was loaded and separated by sodium dodecyl sulfate polyacrylamide gel electrophoresis gels, and then the gels were electrophoretically transferred onto a polyvinylidene fluoride membrane (Beyotime). After blocking with 5\% nonfat dry milk in Tris-buffered saline, the membranes were incubated with antibodies diluted according to the manufacturers' instructions. Secondary antibodies were incubated with antibodies for STAT3 and NQO1 for $1 \mathrm{~h}$ at $25^{\circ} \mathrm{C}$, and the images were captured by the Odyssey Infrared Imaging System (Li-Cor Biosciences, Lincoln, NE). Proteins were quantified using Quantity One imaging software (Bio-Rad Laboratories, Hercules, CA) and normalized with GAPDH.

\section{Results}

Histological changes in ANIT-induced cholestasis rats and GPS-treated groups

ANIT can induce toxicity and cholestasis (Fig. 1). In the GPS-treated group, the area of liver injury decreased significantly and tended towards becoming normal liver tissue; the moderate-dose treatment group showed the most obvious effects (Fig. 1). In our study, serum ALT, ALP, TBA, and TBIL levels increased in the ANIT group, and these were reversed in the GPS group, suggesting severe liver injury and cholestasis. Although UDCA only reversed ALP and TBA, the GPS group reversed all increases in the levels of ALT, ALP, TBA and TBIL, especially in the M-GPS-ANIT group (Table 2). These results suggested that GPS protected against ANIT-induced hepatocyte injury and intrahepatic cholestasis.

\section{Metabolite profiles and markers of ANIT-induced cholestasis}

Representative total ion current chromatograms of serum in the six groups obtained from the positive and negative ion modes are shown in Fig. 2. A PCA model of the serum, liver, and urine metabonomics of each group, and the profiles of the different groups showed a tendency towards separation (Fig. 3). The PLS-DA scores plot (Fig. 4) showed three clusters in the six groups. The ANIT group was clearly separate from the healthy controls. A total of 126 serum metabolites were found to be the most significantly altered in the ANIT group relative to the control. L-GPS-ANIT, M-GPS-ANIT, H-GPS-ANIT, and UDCA groups reversed $92,106,96$, and 39 of these altered metabolites, respectively. In the liver tissue, 109 serum metabolites were altered in the ANIT group compared with the control group. The L-GPSANIT, M-GPS-ANIT, H-GPS-ANIT, and UDCA groups reversed 42, 59, 65, and 30 of these metabolites, respectively. Among the urine metabolites, 99 were identified in the ANIT group compared with the control group. L-GPS-ANIT, M-GPS-ANIT, H-GPS-ANIT, and UDCA groups reversed $70,66,66$, and 54 of these metabolites, respectively. These results indicated that GPS 


\section{Cellular Physiology Cell Physiol Biochem 2018;49:1304-1319

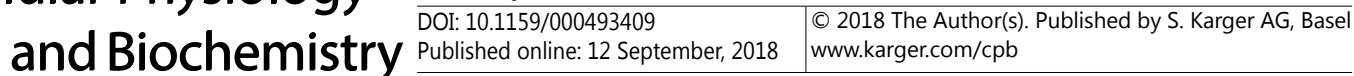 Tong et al.: Omic Study of the Effect of Gentiopicroside on Cholestasis}

can improve ANIT-induced liver injury to a greater degree than the positive drug UDCA. This finding was consistent with the serum biochemical parameters and liver histopathological findings. Five markers in the serum, urine, and liver showed the same changes. A total of 14 markers showed the same changes in sera and urine. Four markers showed the same trend in the sera and liver tissue, and 11 showed the same trend in the urine and liver tissues (Fig. 5, Table 3).

\section{Metabolite markers of cholestasis}

Five differentially expressed metabolites in sera, urine, and liver that are associated with cholestasis (Fig. 5, Table 3) were upregulated in the ANIT group compared with the controls. These metabolites, which included taurallocholic acid, cholic acid, phosphatidylglycerol (PG; 17:0/0:0), tauroursodeoxycholic acid, and phosphatidic acid (PA; 10:0/10:0), could be considered specific potential markers for liver cirrhosis and hepatitis. These metabolites were reversed in the L-GPS-ANIT, M-GPS-ANIT, and H-GPS-ANIT groups in the serum, liver, and urine samples, whereas UDCA could only reverse taurallocholic acid and cholic acid.

\section{DEPS}

A total of 84 proteins, including 31 upregulated- and 53 downregulated-proteins, were differentially expressed in the ANIT group compared with the control group. Additionally, 26 DEPs were reversed in the M-GPS group, while UDCA only reversed 8 proteins (Table 4). Analysis of the cell components revealed that most of the 84 DEPs were annotated cytoplasmic part proteins. From the results obtained from GO analysis, the most significantly enriched pathway was associated with catalytic activity. Analysis of the biological processes showed that these proteins were mainly involved in small molecule metabolism, oxidationreduction, and single-organism metabolism. The upregulated proteins were bile salt export pumps, CP270, cytochrome P450, CYP2C70, STAT3, signal transducer and activator of transcription 4, ABCB4, ATP-binding cassette sub-family D member 3, NQ01, and NAD(P)

Fig. 1. Histological changes in ANIT-induced cholestasis rats and GPS-treated groups; GPS represent the low-dose treatment group (L-GPS, $80 \mathrm{mg} / \mathrm{kg}$ ); M-GPS represent moderate-dose treatment group (M-GPS, $120 \mathrm{mg} / \mathrm{kg}$ ); H-GPS represent high-dose treatment group (H-GPS, $150 \mathrm{~kg} / \mathrm{kg}$ ); and UDCA group represent the UDCA treatment group (70 mg/kg, $\mathrm{n}=12$ ).

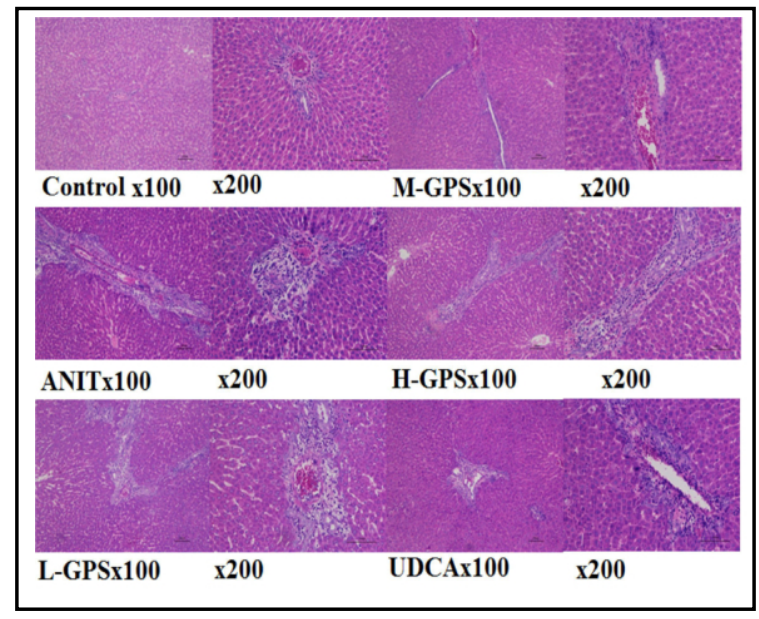

Table 2. Serum Biochemical Parameters in ANIT, GPS, and UDCA groups. Data represent means \pm EM $n=12$. **: versus ANIT, $\mathrm{p}<0.01$; ***: versus ANIT, $\mathrm{p}<0.001$.AST, Glutamic pyruvic transaminase; ALT, aspartate aminotransferase; TBIL, total bilirubin; TBA, total bile acids; ALP, alkaline phosphates; DBIL, Direct Bilirubin

\begin{tabular}{|c|c|c|c|c|c|c|}
\hline & ALT & AST & TBIL & ALP & TBA & DBIL \\
\hline Control & $\begin{array}{c}26.1667 \pm 1.2422 \\
* * *\end{array}$ & $\begin{array}{c}127.0000 \pm 6.1373 \\
* * *\end{array}$ & $\underset{* * *}{.9208 \pm .0502}$ & $\begin{array}{c}631.6667 \pm 34.13062 \\
* * *\end{array}$ & $\underset{* * *}{13.0417 \pm 2.9055}$ & $\begin{array}{c}.0583 \pm .0149 \\
* * *\end{array}$ \\
\hline ANIT & $408.2500 \pm 40.9873$ & $1212.5833 \pm 77.2340$ & $53.0033 \pm 4.3612$ & $1502.6667 \pm 69.9109$ & $497.7000 \pm 23.2832$ & $36.7417 \pm 2.9165$ \\
\hline ANIT+UDCA & $476.8333 \pm 94.4048$ & $1043.5000 \pm 165.2409$ & $40.9517 \pm 9.7137$ & $\begin{array}{c}1164.1667 \pm 129.5369 \\
* * *\end{array}$ & $\begin{array}{c}264.3583 \pm 37.6806 \\
* * *\end{array}$ & $31.6833 \pm 6.2774$ \\
\hline $\begin{array}{l}\text { ANIT+GPS } \\
(80 \mathrm{mg} / \mathrm{kg})\end{array}$ & $\begin{array}{c}192.5000 \pm 47.05501 \\
* *\end{array}$ & $\begin{array}{c}483.7500 \pm 93.24318 \\
* * *\end{array}$ & $\begin{array}{c}4.0050 \pm 1.72221 \\
* * *\end{array}$ & $\begin{array}{c}642.5833 \pm 42.70201 \\
* * *\end{array}$ & $\begin{array}{c}96.9500 \pm 31.0323 \\
* * *\end{array}$ & $\begin{array}{c}2.3750 \pm 1.2546 \\
* * *\end{array}$ \\
\hline $\begin{array}{l}\text { ANIT+GPS } \\
(120 \mathrm{mg} / \mathrm{kg})\end{array}$ & $\begin{array}{c}59.3333 \pm 24.6710 \\
* * *\end{array}$ & $\begin{array}{c}199.5000 \pm 66.5220 \\
* * *\end{array}$ & $\begin{array}{c}1.3267 \pm .57596 \\
* * *\end{array}$ & $\begin{array}{c}590.1667 \pm 50.6929 \\
* * *\end{array}$ & $\begin{array}{c}22.1083 \pm 12.6575 \\
* * *\end{array}$ & $\begin{array}{c}.4417 \pm .3783 \\
* * *\end{array}$ \\
\hline $\begin{array}{l}\text { ANIT+GPS } \\
(150 \mathrm{mg} / \mathrm{kg})\end{array}$ & $\begin{array}{c}105.8333 \pm 36.45355 \\
* * * \\
\end{array}$ & $\begin{array}{c}259.9167 \pm 72.8022 \\
* * *\end{array}$ & $\begin{array}{c}1.4500 \pm .4480 \\
* * *\end{array}$ & $\begin{array}{c}576.0833 \pm 48.6650 \\
* * *\end{array}$ & $\begin{array}{c}36.5250 \pm 13.3655 \\
* * *\end{array}$ & $\begin{array}{c}.5667 \pm .2953 \\
* * *\end{array}$ \\
\hline
\end{tabular}




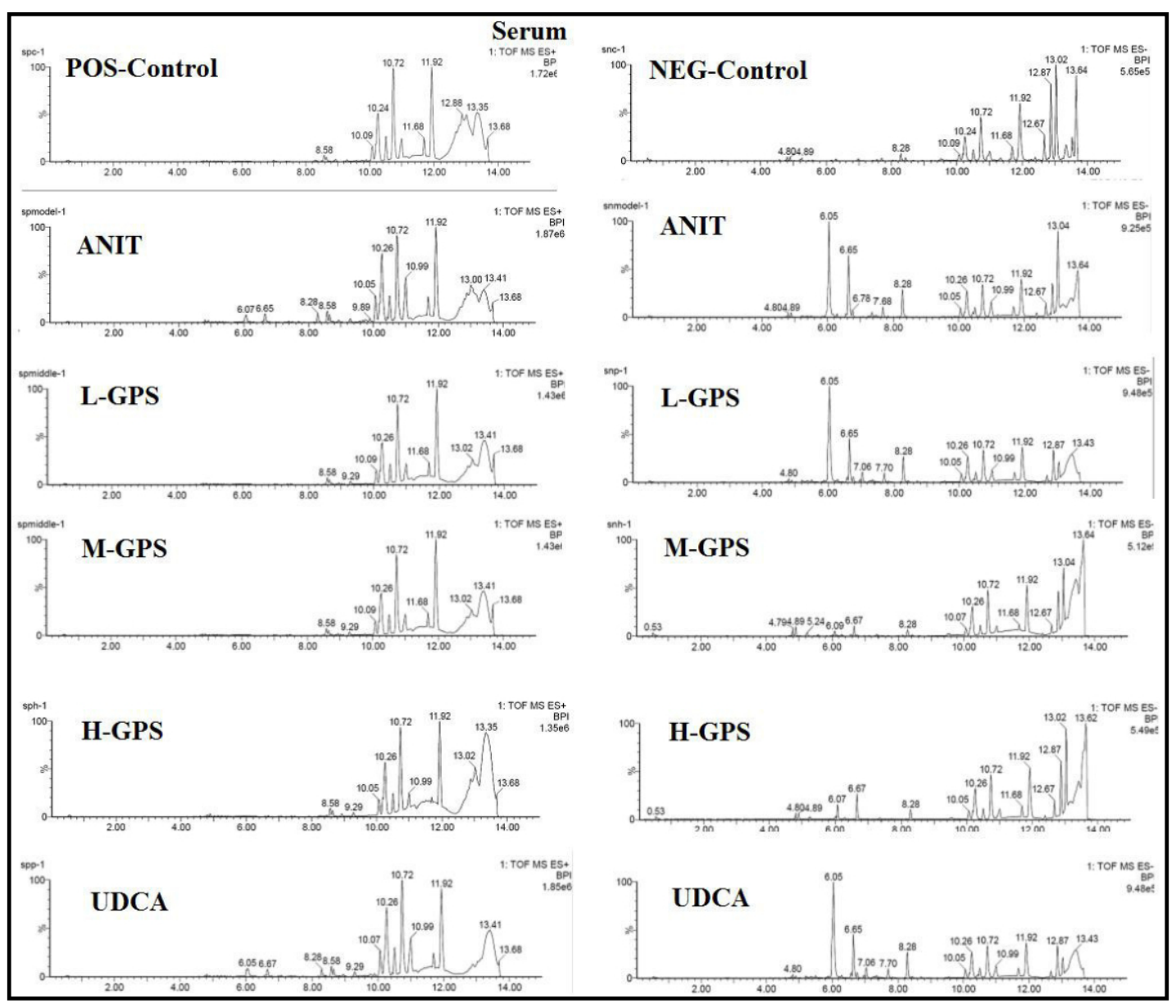

Fig. 2. Representative total ion current chromatograms of the sera in the control, ANIT, L-GPS-ANIT, M-GPSANIT, H-GPS-ANIT, and UDCA-ANIT groups obtained from the UPLC-QTOFMS positive (POS) and negative ion mode(NEG). L-GPS represent the low-dose treatment group (L-GPS, $80 \mathrm{mg} / \mathrm{kg}$ ); M-GPS represent moderatedose treatment group (M-GPS, $120 \mathrm{mg} / \mathrm{kg}$ ); H-GPS represent high-dose treatment group (H-GPS, $150 \mathrm{~kg} /$ $\mathrm{kg}$ ); and UDCA group represent the UDCA treatment group (70 mg/kg, $\mathrm{n=12}$ ).

H dehydrogenase. The downregulated proteins included ACSL1, long-chain-fatty-acid-CoA ligase 1, FMO3, and dimethyl aniline monooxygenase [N-oxide-forming] 3.

\section{Verification of proteomics by western blotting}

The results of proteomics analysis showed upregulated expression levels of STAT3 and NQO1 in the ANIT group (Fig. 6). This result was verified by western blot to detect the expression levels of proteins in the total liver proteins from the ANIT, M-GPS, and control groups. The expression levels of STAT3 and NQO1 in GPS (120 mg/kg) group were downregulated compared with proteins of the ANIT group and upregulated compared with those of the control group. This finding was consistent with the results from proteomics analyses.

\section{Pathway analysis and interactive network of the metabolites and proteins}

The differentially expressed metabolites and proteins (Table 4) were imported into IPA software to review the biological functions, canonical pathways, and significant network analyses. The analyses of diseases and disorders, molecular and cellular functions, and physiological system development and functions were carried out. We systematically evaluated the functions of the identified metabolites and proteins by investigating the results of interactive network analysis (see Supplementary Figure S1 - for all supplementary material see www.karger.com/10.1159/000493409). 


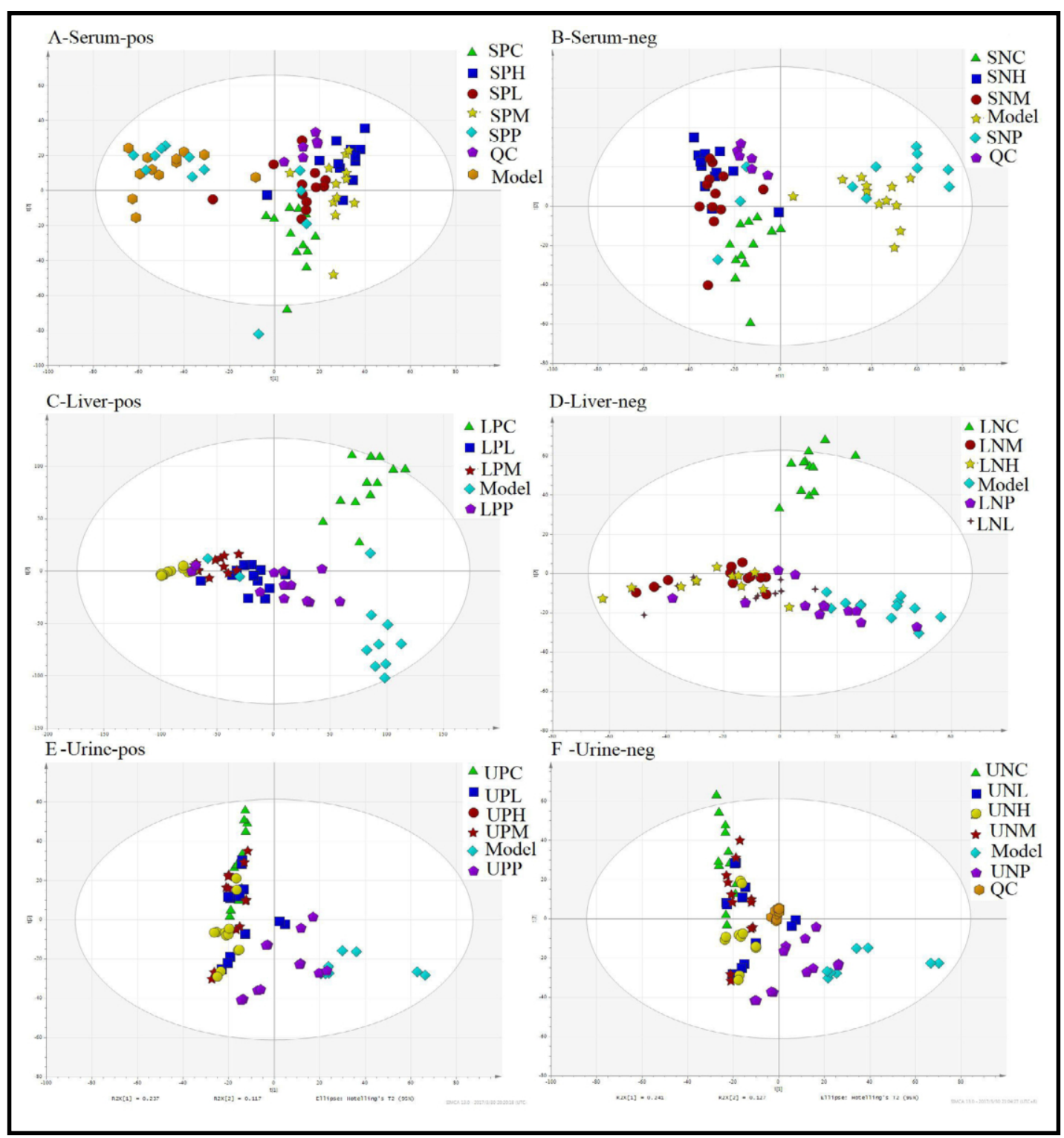

Fig. 3. PCA score plots of the QC group, control, ANIT, L-GPS, M-GPS, H-GPS, and UDCA groups: different shapes represent different groups, (A) Serum-POS-PCA, model and SP-C, L, M, H, P represent the serum positive data from the ANIT, control, L-GPS, M-GPS, H-GPS, and UDCA groups respectively. (B) Serum-NEGPCA; model and SN-C, M, H, P represent the serum negative data from the ANIT, control, M-GPS, H-GPS, and UDCA groups respectively. (C) Liver-POS-PCA; model and LP-C, L, M, H, P represent the liver positive data from the ANIT, control, L-GPS, M-GPS, H-GPS, and UDCA groups respectively. (D) Liver-NEG-PCA; model and LN-C, L, M, H, P represent the liver negative data from the ANIT, control, L-GPS, M-GPS, H-GPS, and UDCA groups respectively. (E) Urine-POS-PCA; model and UP-C, L, M, H, P represent the urine positive data from the ANIT, control, L-GPS, M-GPS, H-GPS, and UDCA groups respectively; and (F) Urine-NEG-PCA. model and SP-C, L, M, H, P represent the serum negative data from the ANIT, control, L-GPS, M-GPS, H-GPS, and UDCA groups respectively. 


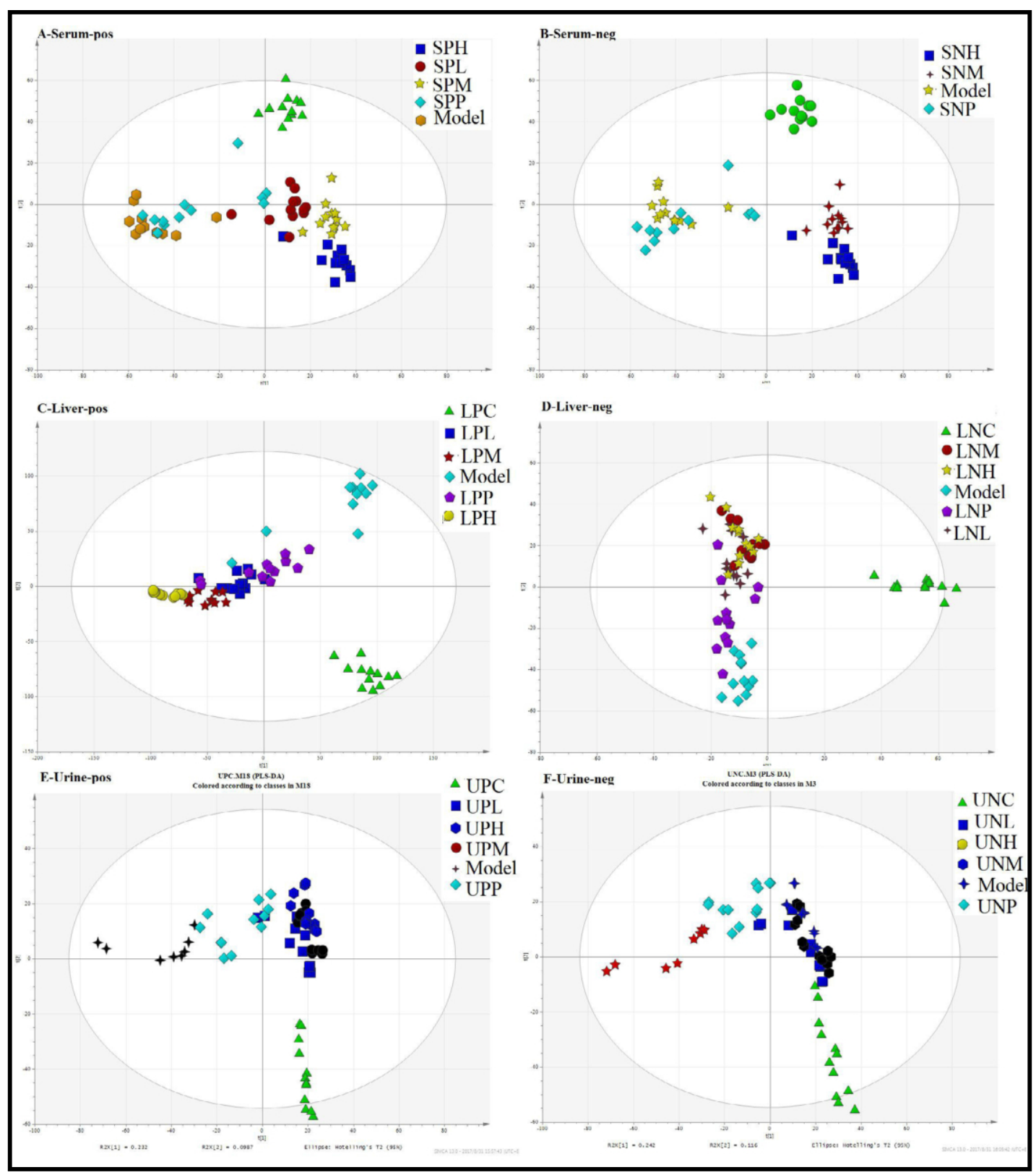

Fig. 4. PLS-DA score plots of the control, ANIT, L-GPS, M-GPS, H-GPS, and UDCA groups: The Notes were as same as Fig. 3, (A) Serum-POS-PLS-DA; (B) Serum-NEG-PLS-DA; (C) Liver-POS-PLS-D; (D) Liver-NEG-PLSDA; (E) Urine-POS-PLS-DA; and (F) Urine-NEG-PLS-DA.

Fig. 5. Venn diagram of the number of overlapping differentially expressed metabolites in the serum, liver, and urine between the ANIT and control groups. Different colors represent different samples.

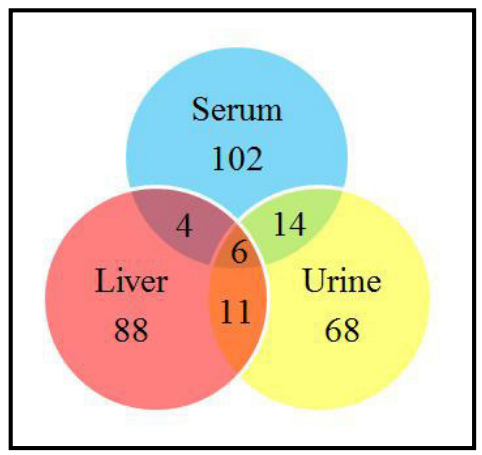


Gene expression in ANITinduced cholestasis rats and the GPS group

The mRNA levels of the transporters and metabolic enzymes were quantified by qRT-PCR (Fig. 7). The results showed that the gene expression levels of FXR, ABCB11, ABCB4, and Mrp4 in the ANIT-treated group significantly decreased $(\# \# \mathrm{p}<0.01, \quad \# \mathrm{p}<0.05$ vs. control; ${ }^{* *} \mathrm{p}<0.01,{ }^{*} \mathrm{p}<0.05$ vs. ANIT). GPS pretreatment significantly upregulated the expression of FXR, Cyp7a1, Mrp4, and ABCB11 mRNA levels than the ANIT group.
Table 3. Differentially expressed metabolites in the serum, liver, and urine between the ANIT and control groups. $\uparrow$ represent upregulated; $\downarrow$ represent downregulated

\begin{tabular}{llllllll}
\hline Name & Serum & Urine & Liver & Name & Serum & Urine & Liver \\
\hline Pateamine & $\uparrow$ & & $\uparrow$ & Carnitine & & $\uparrow$ & $\uparrow$ \\
Taurallocholic acid & $\uparrow$ & $\uparrow$ & $\uparrow$ & Uridine diphosphate & & $\downarrow$ & $\downarrow$ \\
PS(8:0/8:0) & & $\uparrow$ & $\uparrow$ & 3-Indoleacetic Acid & & $\downarrow$ & $\downarrow$ \\
PG(17:0/0:0) & $\uparrow$ & $\uparrow$ & $\uparrow$ & Citric acid & & $\downarrow$ & $\downarrow$ \\
Cholic acid & $\uparrow$ & $\uparrow$ & $\uparrow$ & D-Ribose 5-phosphate & & $\downarrow$ & $\downarrow$ \\
Acetylcarnitine & $\uparrow$ & & $\uparrow$ & Taurine & & $\downarrow$ & $\downarrow$ \\
Tauroursodeoxycholic acid & $\uparrow$ & $\uparrow$ & $\uparrow$ & Phenylalanine & $\downarrow$ & & $\downarrow$ \\
Oleic Acid & $\uparrow$ & & $\uparrow$ & Fumaric acid & & $\downarrow$ & $\downarrow$ \\
PA(10:0/10:0) & $\uparrow$ & $\uparrow$ & $\uparrow$ & PI(17:0/0:0) & $\downarrow$ & & $\downarrow$ \\
Stearoylcarnitine & $\uparrow$ & & $\uparrow$ & D-Glucose 6-phosphate & & $\downarrow$ & $\downarrow$ \\
PG(16:1(9Z)/0:0) & $\uparrow$ & $\uparrow$ & & PI(12:0/0:0) & $\uparrow$ & $\uparrow$ & \\
PC(18:0/0:0) & $\uparrow$ & $\uparrow$ & & PI(P-18:0/0:0) & $\uparrow$ & $\uparrow$ & \\
PI(P-16:0/0:0) & $\uparrow$ & $\uparrow$ & & PS(16:1(9Z)/0:0) & $\uparrow$ & $\uparrow$ & \\
PS(10:0/10:0) & $\uparrow$ & $\uparrow$ & & Valine & $\uparrow$ & $\uparrow$ & \\
7-ketodeoxycholic acid & $\uparrow$ & $\uparrow$ & & Choline & $\uparrow$ & & \\
Sphinganine-phosphate & $\uparrow$ & $\uparrow$ & & PG(P-18:0/0:0) & $\uparrow$ & $\uparrow$ & \\
PC(16:1(9Z)/0:0) & $\uparrow$ & $\uparrow$ & & & & & \\
\hline
\end{tabular}

\section{Discussion}

Cholestasis is one of the most common and devastating liver diseases. This disease is characterized by dysfunction of hepatocytes or obstruction of bile ducts, resulting in the accumulation of toxic BAs in the liver [26]. In cholestasis, serum and liver BA levels are elevated and result in hepatic injury. To date, the pathogenesis of BA-induced liver injury remains ambiguous, and the treatment options are limited [27]. Currently, UDCA is the only widely used drug for treating cholestatic diseases. However, the efficacy of UDCA is inconsistent and it is ineffective in some patients [11]. According to previous studies, GPS has an anti-cholestatic effect and could be considered as an alternative to UDCA, although the mechanism is still unclear. In this report, conventional methods were used to study the effects of GPS on cholestasis. We identified differences among the proteins and metabolites between normal, ANIT-induced cholestatic samples, and GPS-treated samples using proteomics and metabolomics to evaluate the mechanism of BA-induced liver damage and determine the possible protective mechanism of GPS in ANIT-induced liver injury. We built the proteins and metabolite interaction network of GPS against cholestasis. The results showed that GPS had protective effects on cholestasis by reversing potential biomarkers to normal levels. Moreover, 36 metabolites were regulated in the primary BA biosynthesis pathway, in glycerophospholipid metabolism, and in FAs metabolism. GPS, especially at the moderate dose, could reverse most of these effects. Taurallocholic acid, cholic acid, PG (17:0/0:0), tauroursodeoxycholic acid, and PA (10:0/10:0) were upregulated in sera, the liver, and urine. This result suggested that these metabolites might be biomarkers of cholestasis.

Glycerophospholipid metabolism focuses on phosphocholines (PCs), PGs, and PAs, which are the main lipid components of biomembranes. PC molecules are involved in many biological processes such as cell signaling, energy metabolism and storage, and cell membrane integrity. In our study, PCs were increased in the ANIT group, and the activation of lipid metabolism indicated an attempt to repair and reduce cell membrane and cell damage [28]. Recent studies have also shown that increasing levels of phosphatidylcholine can reduce the levels of cholesterol and reduce liver damage effects in the body [29]. In addition, taurocholic acid, glycocholic acid, taurochenodeoxycholic acid, and glycochenodeoxycholic acid were upregulated significantly in the ANIT group versus the control group, but GPS downregulated the levels of these metabolites remarkably in the serum, urine, and liver. The levels of these BAs are elevated in patients with cholestasis [10]. The accumulation of several hydrophobic BAs during cholestasis leads to apoptosis and inflammation in hepatocytes [30]. Network analysis revealed that BA biosynthesis was activated, and CYP3A4, CYP3A, and CYP7A1 were found to be involved in the biosynthesis of BAs (Supplementary Figure S1). qRT-PCR results confirmed that CYP7A1 was upregulated in the ANIT group, and GPS treatment could reverse 


\section{Cellular Physiology and Biochemistry

Table 4. Dysregulated Proteins in different groups. $\uparrow$ represent upregulated; $\downarrow$ represent downregulated

\begin{tabular}{|c|c|c|c|c|c|}
\hline ID & Uniprot name & Name & ANIT/Control & GPS/ANIT & UDCA/ANIT \\
\hline P01026 & CO3_RAT & Complement C3 & $\uparrow$ & $\downarrow$ & \\
\hline P02680 & FIBG_RAT & Fibrinogen gamma chain & $\uparrow$ & $\downarrow$ & \\
\hline P05982 & NQ01_RAT & NAD(P)H dehydrogenase & $\uparrow$ & $\downarrow$ & \\
\hline P06399 & FIBA_RAT & Fibrinogen alpha chain & $\uparrow$ & $\downarrow$ & \\
\hline P06866 & HPT_RAT & Haptoglobin & $\uparrow$ & $\downarrow$ & \\
\hline P09006 & SPA3N_RAT & Serine protease inhibitor A3N & $\uparrow$ & $\downarrow$ & \\
\hline P13635 & CERU_RAT & Ceruloplasmin & $\uparrow$ & $\downarrow$ & \\
\hline P14480 & FIBB_RAT & Fibrinogen beta chain & $\uparrow$ & $\downarrow$ & \\
\hline P17425 & HMCS1_RAT & Hydroxymethylglutaryl-CoA synthase, cytoplasmic & $\uparrow$ & $\downarrow$ & \\
\hline P19225 & CP270_RAT & Cytochrome P450 2C70 & $\uparrow$ & $\downarrow$ & \\
\hline P52631 & STAT3_RAT & Signal transducer and activator of transcription 3 & $\uparrow$ & $\downarrow$ & \\
\hline Q62667 & MVP_RAT & Major vault protein & $\uparrow$ & $\downarrow$ & \\
\hline 088618 & FTCD_RAT & Formimidoyltransferase-cyclodeaminase & $\downarrow$ & $\uparrow$ & $\uparrow$ \\
\hline P28037 & AL1L1_RAT & Cytosolic 10-formyltetrahydrofolate dehydrogenase & $\downarrow$ & $\uparrow$ & $\uparrow$ \\
\hline Q63108 & EST1E_RAT & Carboxylesterase $1 \mathrm{E}$ & $\downarrow$ & $\uparrow$ & $\uparrow$ \\
\hline P00481 & OTC_RAT & Ornithine carbamoyltransferase, mitochondrial $\mathrm{OS}=$ Rattus norvegicus $\mathrm{GN}=0$ tc $\mathrm{PE}=1 \mathrm{SV}=1$ & $\downarrow$ & $\uparrow$ & \\
\hline P00507 & AATM_RAT & Aspartate aminotransferase, mitochondrial & $\downarrow$ & $\uparrow$ & \\
\hline P02761 & MUP_RAT & Major urinary protein & $\downarrow$ & $\uparrow$ & \\
\hline P05182 & CP2E1_RAT & Cytochrome P450 2E1 & $\downarrow$ & $\uparrow$ & \\
\hline P08683 & CP2CB_RAT & Cytochrome P450 2C11 & $\downarrow$ & $\uparrow$ & \\
\hline P12938 & CP2D3_RAT & Cytochrome P450 2D3 & $\downarrow$ & $\uparrow$ & \\
\hline P16303 & CES1D_RAT & Carboxylesterase 1D & $\downarrow$ & $\uparrow$ & \\
\hline P52759 & UK114_RAT & Ribonuclease UK114 & $\downarrow$ & $\uparrow$ & \\
\hline Q63120 & MRP2_RAT & Canalicular multispecific organic anion transporter 1 & $\downarrow$ & $\uparrow$ & \\
\hline Q6AYS8 & DHB11_RAT & Estradiol 17-beta-dehydrogenase 11 & $\downarrow$ & $\uparrow$ & \\
\hline Q6UPE0 & CHDH_RAT & Choline dehydrogenase, mitochondrial & $\downarrow$ & $\uparrow$ & \\
\hline Q9EQ76 & FMO3_RAT & Dimethylaniline monooxygenase [N-oxide-forming] 3 & $\downarrow$ & $\uparrow$ & \\
\hline Q9Z0U5 & AOXA_RAT & Aldehyde oxidase 1 & $\uparrow$ & & $\downarrow$ \\
\hline 009171 & BHMT1_RAT & Betaine--homocysteine S-methyltransferase 1 & $\downarrow$ & & $\uparrow$ \\
\hline P15999 & ATPA_RAT & ATP synthase subunit alpha, mitochondrial & $\downarrow$ & & $\uparrow$ \\
\hline P18163 & ACSL1_RAT & Long-chain-fatty-acid--CoA ligase 1 & $\downarrow$ & & $\uparrow$ \\
\hline Q4KLZ6 & TKFC_RAT & Triokinase/FMN cyclase & $\downarrow$ & & $\uparrow$ \\
\hline D3ZHV2 & MACF1_RAT & Microtubule-actin cross-linking factor 1 & $\uparrow$ & & \\
\hline 008651 & SERA_RAT & D-3-phosphoglycerate dehydrogenase & $\uparrow$ & & \\
\hline 070127 & ABCBB_RAT & Bile salt export pump & $\uparrow$ & & \\
\hline 070351 & HCD2_RAT & 3-hydroxyacyl-CoA dehydrogenase type- 2 & $\downarrow$ & & \\
\hline P00884 & ALDOB_RAT & Fructose-bisphosphate aldolase B & $\downarrow$ & & \\
\hline P02650 & APOE_RAT & Apolipoprotein E & $\uparrow$ & & \\
\hline P04176 & PH4H_RAT & Phenylalanine-4-hydroxylase & $\downarrow$ & & \\
\hline P04636 & MDHM_RAT & Malate dehydrogenase, mitochondrial & $\downarrow$ & & \\
\hline P04642 & LDHA_RAT & L-lactate dehydrogenase A chain & $\downarrow$ & & \\
\hline P05183 & CP3A2_RAT & Cytochrome $\mathrm{P} 4503 \mathrm{~A} 2$ & $\downarrow$ & & \\
\hline P05369 & FPPS_RAT & Farnesyl pyrophosphate synthase & $\uparrow$ & & \\
\hline P06757 & ADH1_RAT & Alcohol dehydrogenase 1 & $\downarrow$ & & \\
\hline P07379 & PCKGC_RAT & Phosphoenolpyruvate carboxykinase, cytosolic [GTP] & $\downarrow$ & & \\
\hline P09811 & PYGL_RAT & Glycogen phosphorylase, liver form & $\downarrow$ & & \\
\hline P10760 & SAHH_RAT & Adenosylhomocysteinase & $\downarrow$ & & \\
\hline P10860 & DHE3_RAT & Glutamate dehydrogenase 1 , mitochondrial & $\downarrow$ & & \\
\hline P11884 & ALDH2_RAT & Aldehyde dehydrogenase, mitochondrial & $\downarrow$ & & \\
\hline P12346 & TRFE_RAT & Serotransferrin & $\uparrow$ & & \\
\hline P13255 & GNMT_RAT & Glycine N-methyltransferase & $\downarrow$ & & \\
\hline P13601 & AL1A7_RAT & Aldehyde dehydrogenase, cytosolic 1 & $\uparrow$ & & \\
\hline P14141 & CAH3_RAT & Carbonic anhydrase 3 & $\downarrow$ & & \\
\hline P14604 & ECHM_RAT & Enoyl-CoA hydratase, mitochondrial & $\downarrow$ & & \\
\hline P15083 & PIGR_RAT & Polymeric immunoglobulin receptor & $\uparrow$ & & \\
\hline P15149 & CP2A2_RAT & Cytochrome P450 2A2 & $\downarrow$ & & \\
\hline P16970 & ABCD3_RAT & ATP-binding cassette sub-family D member 3 & $\uparrow$ & & \\
\hline P22789 & ST2A2_RAT & Alcohol sulfotransferase A & $\uparrow$ & & \\
\hline P22791 & HMCS2_RAT & Hydroxymethylglutaryl-CoA synthase, mitochondrial & $\downarrow$ & & \\
\hline P29147 & BDH_RAT & D-beta-hydroxybutyrate dehydrogenase, mitochondrial & $\downarrow$ & & \\
\hline P31044 & PEBP1_RAT & Phosphatidylethanolamine-binding protein 1 & $\downarrow$ & & \\
\hline P32198 & CPT1A_RAT & Carnitine 0-palmitoyltransferase 1 , liver isoform & $\downarrow$ & & \\
\hline P37397 & CNN3_RAT & Calponin-3 & $\uparrow$ & & \\
\hline P50137 & TKT_RAT & Transketolase & $\downarrow$ & & \\
\hline P52873 & PYC_RAT & Pyruvate carboxylase, mitochondrial & $\downarrow$ & & \\
\hline P55159 & PON1_RAT & Serum paraoxonase/arylesterase 1 & $\downarrow$ & & \\
\hline P63036 & DNJA1_RAT & DnaJ homolog subfamily A member 1 & $\downarrow$ & & \\
\hline P70584 & ACDSB_RAT & Short/branched chain specific acyl-CoA dehydrogenase, mitochondrial & $\downarrow$ & & \\
\hline Q02253 & MMSA_RAT & Methylmalonate-semialdehyde dehydrogenase [acylating], mitochondrial & $\downarrow$ & & \\
\hline Q02769 & FDFT_RAT & Squalene synthase & $\uparrow$ & & \\
\hline Q03626 & MUG1_RAT & Murinoglobulin-1 & $\downarrow$ & & \\
\hline Q08201 & MDR3_RAT & Phosphatidylcholine translocator ABCB4 & $\uparrow$ & & \\
\hline Q58FK9 & KAT3_RAT & Kynurenine--oxoglutarate transaminase 3 & $\downarrow$ & & \\
\hline Q5M7W5 & MAP4_RAT & Microtubule-associated protein 4 & $\uparrow$ & & \\
\hline Q5PPL3 & NSDHL_RAT & Sterol-4-alpha-carboxylate 3-dehydrogenase, decarboxylating & $\uparrow$ & & \\
\hline Q62930 & CO9_RAT & Complement component C9 & $\uparrow$ & & \\
\hline Q63060 & GLPK_RAT & Glycerol kinase & $\downarrow$ & & \\
\hline Q64654 & CP51A_RAT & Lanosterol 14-alpha demethylase & $\uparrow$ & & \\
\hline Q6IRK9 & CBPQ_RAT & Carboxypeptidase Q & $\downarrow$ & & \\
\hline Q7TMA5 & APOB_RAT & Apolipoprotein B-100 & $\uparrow$ & & \\
\hline Q7TP48 & APMAP_RAT & Adipocyte plasma membrane-associated protein & $\downarrow$ & & \\
\hline Q80Z29 & NAMPT_RAT & Nicotinamide phosphoribosyltransferase & $\downarrow$ & & \\
\hline Q9JLJ3 & AL9A1_RAT & 4-trimethylaminobutyraldehyde dehydrogenase & $\downarrow$ & & \\
\hline Q9Z1A6 & VIGLN_RAT & Vigilin & $\downarrow$ & & \\
\hline
\end{tabular}


Fig. 6. Western blot analyses of STAT3 and NQ01protein levels in the control and model (ANIT), GPS, positive (UDCA) group. Quantification of the protein expressions was performed by densitometric analysis of the blots following normalization to Graph expression. Data represent means \pm SEM, ${ }^{* *} \mathrm{p}<0.01,{ }^{*} \mathrm{p}<0.05$ vs. model group by one-way ANOVA.

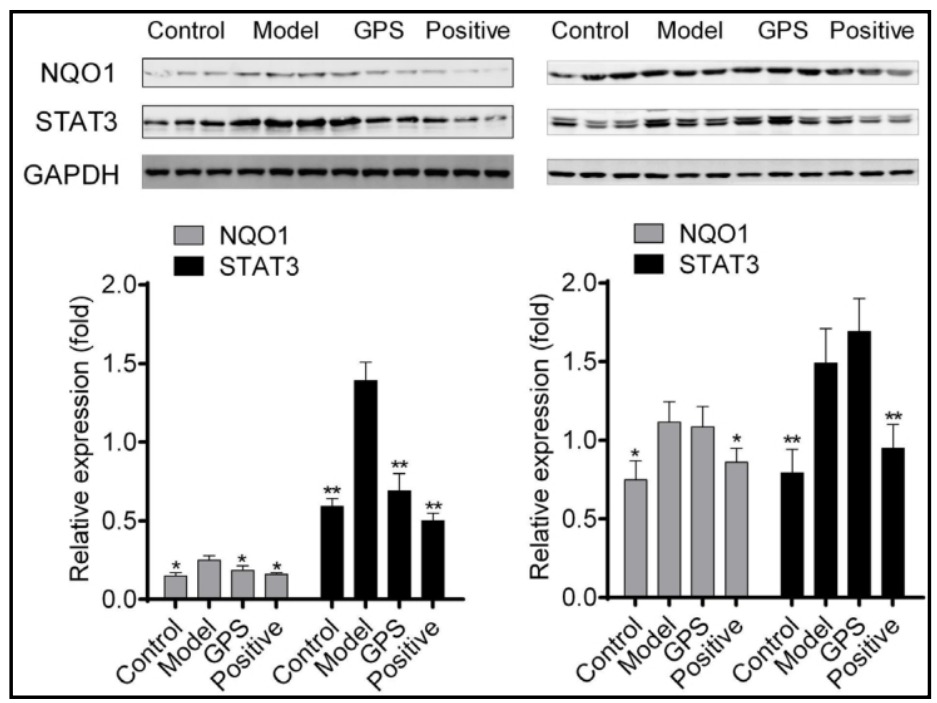

Fig. 7. Expression of genes involved in BA synthesis, transportation, and reabsorption in different groups as detected by qRTPCR ( $n=3$ rats per group). Data represent means \pm SEM; \#\# $\mathrm{p}<0.01$, \# $\mathrm{p}<0.05$ vs. control; ${ }^{* *} \mathrm{p}<0.01,{ }^{*} \mathrm{p}<0.05$ vs. ANIT group by one-way ANOVA. M-GPS represent moderate-dose treatment group (M-GPS, $120 \mathrm{mg} / \mathrm{kg}$ ); Foresaid X Receptor (FXR),

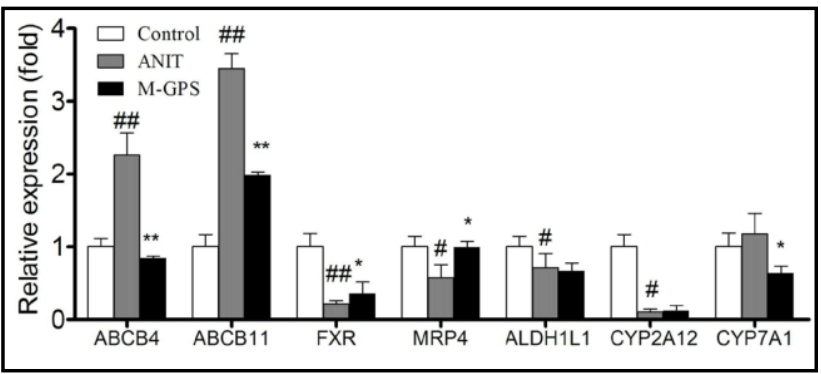
cholesterol 7-alpha hydroxy-lase(Cyp7a1), multidrug resistance protein 4(Mrp4) and ATP binding cassette subfamily B member 4,11 (ABCB4, 11); Aldehyde dehydrogenase family 1-member L1(ALDH1L1); Steroid hormones 7-alpha-hydroxylase (CYP2A12).

this effect. CYP7A1 was the rate-limiting enzyme in the synthesis of BAs. GPS inhibited the expression of CYP7A1 to reduce the biosynthesis of BAs, thus the process could protect the liver from injury induced by BAs. These results may partially indicate a possible therapeutic mechanism through BA synthesis and secretion.

Proteomics analyses of the liver identified 53 downregulated and 31 upregulated proteins in the ANIT group versus the control group. The DEPs were primarily involved in the oxidation of FAs and lipid metabolism. FAs beta-oxidation plays a key role in liver steatosis, fibrosis, and eventually cirrhosis [31,32]. Canonical pathway analyses of differentially expressed metabolites and DEPs were performed in the ANIT group and compared with the control group. The top five pathways associated with cholestasis, LXR/retinoid X receptor (RXR), and FXR/RXR activation were found to be significantly different. Previous studies indicated that LXR is involved in cholesterol and lipid metabolism and orchestrates the inflammatory response by inhibiting the expression of inflammatory mediators stimulated by LPS, tumor necrosis factor- $\alpha$, and interleukin-1 $\beta$ [33-35]. FXR, which is an endogenous and physiologically relevant ligand, and one of the most important upstream nuclear receptors. Recent studies have suggested that FXR has a complementary role in the regulation of genes in the synthesis and transport of BAs [36, 37]. Cholestasis-related transporters and enzymes have adaptive responses through the activation of FXR, indicating that FXR may become the focus of targeted therapies in cholestasis as the key regulatory transcription factor for BA [38]. FXR can suppress the expression of Cyp7a1, the rate-limiting enzyme in BA synthesis [39]. The loss of FXR can rapidly result in cholestasis and liver injury [40]. A moderate dose of GPS $(120 \mathrm{mg} / \mathrm{kg})$ could significantly upregulate the expression of FXR, which may suppress the expression of CYP7A1. These results were confirmed by qRT-PCR (Fig. 7). In addition, GPS was shown to significantly upregulate the expression of Mrp4 mRNA in rat livers at 
a dose of $120 \mathrm{mg} / \mathrm{kg}$. Mrp4 can transport BAs from the hepatocytes into the bile [41]. The elevation of Mrp4 could facilitate hepatic BAs into the canaliculus and thus reduce the risk of liver injury. In addition, Mrp4 mediates the export of bilirubin conjugates from hepatocytes [42]. Studies have reported that ATP-binding cassette (ABC) transporters are responsible for transporting BAs across the canalicular membrane against their concentration gradients. The bile salt export pumps (ABCB11 and ABCB4)

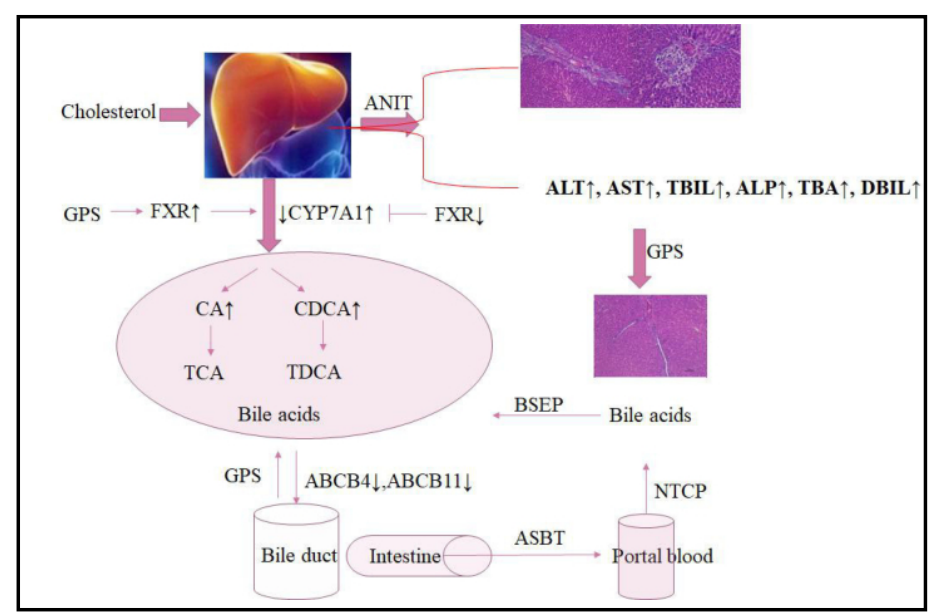

Fig. 8. A probable mechanism of liver cirrhosis and GPS action figure are mainly responsible for $\mathrm{BA}$ transport from the hepatocytes into the bile canaliculi. In the current study, GPS treatment significantly suppressed the expression of ABC11 and ABCB4 (Fig. 7). This result indicated that GPS could prevent BAs from refluxing into the liver against their concentration gradients and reduce ANIT-induced liver injury. As a summary, we produced a brief GPS action diagram (Fig. 8). GPS can up-regulate the expression of FXR, inhibit the synthesis of CYP7A1, reduce the synthesis of $B A s$, and accelerate the secretion of bile into the bile ducts from the liver by upregulating the expression of $\mathrm{ABCB} 4$ and $\mathrm{ABCB} 11$.

\section{Conclusion}

In this study, we analyzed ANIT-induced cholestasis using i-TRAQ and metabolic profiles of liver tissue extracts, serum, and urine. A series of proteins and metabolic intermediates were altered during the development of liver injury. These compounds were mainly involved in the metabolism of BAs, FAs and lipids. GPS effectively compensated as shown by shifts in the expression of FXR, ABCB11, ABCB4, CYP7A1, ALDH1L1, and Mrp4, and this effect could prevent hepatic BA accumulation and liver injury. These findings indicated a potential novel and sequential mechanism for the initiation of ANIT-induced liver injury in cholestasis and highlighted several potential therapeutic interventions.

\section{Abbreviations}

ANIT (alpha-naphthylisothiocyanate); GPS (gentiopicroside); BA (bile acid); qRTPCR (quantitative real-time polymerase chain reaction); UDCA (ursodeoxycholic acid); ALP (alkaline phosphatase); TBIL (total bilirubin); AST (aspartate aminotransferase); ALT (alanineaspartate aminotransferase); TBA (total bile acid); TBIL (total bilirubin); DBIL (direct bilirubin); PCA (principal components analysis); PLS-DA (partial-least-squares discriminate analysis); IPA (Ingenuity Pathway Analysis); PC (phosphocholine); PG (phosphatidylglycerol); PA (phosphatidic acid); FXR (farnesoid X receptor); RXR (retinoid $\mathrm{X}$ receptor); DEP (differentially expressed protein); H\&E (hematoxylin and eosin); VIP (variable importance in the projection); KEGG (Kyoto Encyclopedia of Genes and Genomes); MS (mass spectrometry); MS/MS (tandem mass spectrometry); LC (liquid chromatography); FAs (fatty acids); GO (Gene Ontology). 


\section{Cellular Physiology Cell Physiol Biochem 2018;49:1304-1319 \begin{tabular}{l|l|l} 
and Biochemistry & $\begin{array}{l}\text { DOI: } 10.1159 / 000493409 \\
\text { Published online: } 12 \text { September, } 2018\end{array}$ & $\begin{array}{l}\text { @ } 2018 \text { The Author(s). Published by S. Karger AG, Basel } \\
\text { www.karger.com/cpb }\end{array}$ \\
\hline
\end{tabular}

\section{Acknowledgements}

This work was financially supported by National Natural Science Foundation of China (project No. 81503223, 81403034) and Xinglin Talent Program of Shanghai University of Traditional Chinese Medicine.

\section{Disclosure Statement}

The authors declare no conflicts of interest.

\section{References}

1 Li T, Chiang JYL: Bile acids as metabolic regulators. Curr Opin Gastroenterol 2015;31:159-165.

-2 Pauli-Magnus C, Meier PJ: Hepatobiliary transporters and drug-induced cholestasis. Hepatology 2006;44:778-787.

3 Palmeira CM, Rolo AP: Mitochondrially-mediated toxicity of bile acids. Toxicology 2004;203:1-15.

4 Malhi H, Guicciardi ME, Gores GJ: Hepatocyte death: a clear and present danger. Physiol Rev 2010;90:11651194.

5 Faubion WA, Guicciardi ME, Miyoshi H, Bronk SF, Roberts PJ, Svingen PA, Kaufmann SH, Gores GJ: Toxic bile salts induce rodent hepatocyte apoptosis via direct activation of Fas. J Clin Invest 1999;103:137-145.

6 Higuchi H, Bronk SF, Takikawa Y, Werneburg N, Takimoto R, El-Deiry W, Gores GJ: The bile acid glycochenodeoxycholate induces TRAIL-receptor 2/DR5 expression and apoptosis. J Biol Chem 2001;276:38610-38618.

7 Fickert P, Wagner M, Marschall HU, Fuchsbichler A, Zollner G, Tsybrovskyy O, Zatloukal K, Liu J, Waalkes MP, Cover C, Denk H, Hofman AF, JaeschkeH, Trauner M: 24-norUrsodeoxycholic acid is superior to ursodeoxycholic acid in the treatment of sclerosing cholangitis in Mdr2 (Abcb4) knockout mice. Gastroenterology 2006;130:465-481.

-8 Zhang Y, Hong J-Y, Rockwell CE, Copple BL, Jaeschke H, Klaassen CD, Effect of bile duct ligation on bile acid composition in mouse serum and liver. Liver Int 2012;32:58-69.

-9 Woolbright BL, Antoine DJ, Jenkins RE, Bajt ML, Park BK, Jaeschke H, Plasma biomarkers of liver injury and inflammation demonstrate a lack of apoptosis during obstructive cholestasis in mice. Toxicol Appl Pharmacol 2013;273:524-531.

10 Woolbright BL, Dorko K, Antoine DJ, Clarke JI, Gholami P, Li F, Kumer SC, Schmitt TM, Forster J, Fan F, Jenkins RE, Park BK, Hagenbuch B, Olyaee M, Jaeschke H: Bile acid-induced necrosis in primary human hepatocytes and in patients with obstructive cholestasis. Toxicol Appl Pharmacol 2015;283:168-177.

11 Jones DE, Al-Rifai A, Frith J, Patanwala I, Newton JL: The independent effects of fatigue and UDCA therapy on mortality in primary biliary cirrhosis: Results of a 9 year follow-up. J Hepatol 2010;53:911-917.

$\$ 12$ Hirschfield GM, Heathcote EJ, Gershwin ME: Pathogenesis of cholestatic liver disease and therapeutic approaches. Gastroenterology 2010;139:1481-1496.

13 Kondo Y, Takano F, Hojo H: Suppression of chemically and immunologically induced hepatic injuries by gentiopicroside in mice. Planta Med 1994;60:414-416.

14 Lian LH, WuYL, Song SZ, Wan Y, Xie WX, Li X, Bai T, Ouyang BQ, Nan JX: Gentiana manshurica Kitagawa reverses acute alcohol-induced liver steatosis through blocking sterol regulatory element-binding protein-1 maturation. J Agric Food Chem 2010;58:13013-13019.

15 Wang AY, Lian LH, Jiang YZ, Wu YL, Nan JX: Gentiana manshurica Kitagawa prevents acetaminopheninduced acute hepatic injury in mice via inhibiting JNK/ERK MAPK pathway. World J Gastroenterol 2010;16:384-391.

16 Wang H, Wu G, Park HJ, Jiang PP, Sit WH, van Griensven LJLD, Wan JMF: Protective effect of Phellinus linteus polysaccharide extracts against thioacetamide-induced liver fibrosis in rats: a proteomics analysis. Chin Med 2012;7:23-33.

17 Lee TY, Chang HH, Kuo JJ, Shen JJ: Changes of hepatic proteome in bile duct ligated rats with hepatic fibrosis following treatment with Yin-Chen-Hao-Tang. Int J Mol Med 2009;23:477-484. 


\section{Cellular Physiology Cell Physiol Biochem 2018;49:1304-1319 \begin{tabular}{l|l} 
DOI: 10.1159/000493409 & $\begin{array}{l}\text { O } 2018 \text { The Author(s). Published by S. Karger AG, Basel } \\
\text { www.karger.com/cpb }\end{array}$ \\
\cline { 2 - 3 } 12 September, 2018
\end{tabular} \\ Tong et al:: Omic Study of the Effect of Gentiopicroside on Cholestasis}

18 Xuan J, Wen W, Wang Y, Wang F, Xu HB, Shao M, Yang Y, Tian YZ. Effect of Huagantongluofang, a Chinese Traditional Medicine, in Hepatic Fibrogenesis in a Mouse Model of Biliary Cirrhosis. Cell Physiol Biochem. 2017;44:368-376.

19 Shao Y, Chen J, Zheng J, Liu CR. Effect of Histone Deacetylase HDAC3 on Cytokines IL-18, IL-12 and TNF- $\alpha$ in Patients with Intrahepatic Cholestasis of Pregnancy. Cell Physiol Biochem. 2017;42:1294-1302.

20 Becker S, Reinehr R, Graf D, vom Dahl S, Häussinger D. Hydrophobic bile salts induce hepatocyte shrinkage via NADPH oxidase activation. Cell Physiol Biochem. 2007;19:89-98.

-21 Yang L, Rudser KD, Higgins L, Rosen HR, Zaman A, Corless CL, David L, Gourley GR: Novel biomarker candidates to predict hepatic fibrosis in hepatitis C identified by serum proteomics. Dig Dis Sci 2011;56:3305-3315.

22 Zhang L, Jia X, FengY, Peng X, Zhang Z, Zhou W, Zhang Z, Ma F, Liu X, Zheng Y, Yang P, Yuan Z: Plasma membrane proteome analysis of the early effect of alcohol on liver: implications for alcoholic liver disease. Acta Biochim Biophys Sin 2011;43:19-29.

-23 Gowert NS, Klier M, Reich M, Reusswig F, Donner L, Keitel V, Häussinger D, Elvers M. Defective Platelet Activation and Bleeding Complications upon Cholestasis in Mice. Cell Physiol Biochem. 2017;41:21332149.

24 Nicholson JK, Lindon JC, HolmesE: 'Metabonomics': understanding the metabolic responses of living systems to pathophysiological stimuli via multivariate statistical analysis of biological NMR spectroscopic data. Xenobiotica 1999;29:1181-1189.

25 Chen Z, Zhu Y, Zhao Y, Ma X, Niu M, Wang J, Su H, Wang R, Li J, Liu W, Wei Z, Zhao Q, Chen H, Xiao X: serum metabolomic profiling in a rat model Reveals protective function of paeoniflorin against ANIT induced cholestasis. Phytother Res 2016;30:654-662.

-26 Modica S, Petruzzelli M, BellafanteE, Murzilli S, Salvatore L, Celli N, Di Tullio G, Palasciano G, Moustafa T, Halilbasic E, Trauner M, Moschetta A: Selective activation of nuclear bile acid receptor FXR in the intestine protects mice against cholestasis. Gastroenterology 2012;142:355-365.

27 Beuers U, Trauner M, Jansen P, Poupon R: New paradigms in the treatment of hepatic cholestasis: From UDCA to FXR, PXR and beyond. J Hepatol 2015;62:S25-S37.

-28 Wright MM, Howe AG, Zaremberg V: Cell membranes and apoptosis: role of cardiolipin, phosphatidylcholine, and anticancer lipid analogues. Biochem Cell Biol 2004;82:18-26.

29 Volinsky R, Paananen R, Kinnunen PKJ: Oxidized phosphatidylcholines promote phase separation of cholesterol-sphingomyelin domains. Biophys J 2012;103:247-254.

-30 Dilger K, Hohenester S, Winkler-Budenhofer U, Bastiaansen BAJ, Schaap FG, Rust C, Beuers U: Effect of ursodeoxycholic acid on bile acid profiles and intestinal detoxification machinery in primary biliary cirrhosis and health. J Hepatol 2012;57:133-140.

-31 Wei Y, Clark SE, Thyfault JP, Uptergrove GME, Li W, Whaley-Connell AT, Ferrario CM, Sowers JR, Ibdah JA: Oxidative stress-mediated mitochondrial dysfunction contributes to angiotensin II-induced nonalcoholic fatty liver disease in transgenic ren2 rats. Am J Pathol 2009;174:1329-1337.

-32 Mantena SK, King AL, Andringa KK, Eccleston HB, Bailey SM: Mitochondrial dysfunction and oxidative stress in the pathogenesis of alcohol- and obesity-induced fatty liver diseases. Free Radic Biol Med 2008;44:1259-1272.

-33 Fowler AJ, Sheu MY, Schmuth M, Kao J, Fluhr JW, Rhein L, Collins JL, Willson TM, Mangelsdorf DJ, Elias PM, Feingold KR: Liver X receptor activators display anti-inflammatory activity in irritant and allergic contact dermatitis models: liver-X-receptor-specific inhibition of inflammation and primary cytokine production. J Invest Dermatol 2003;120:246-255.

34 Ogawa S, Lozach J, Benner C, Pascual G, Tangirala RK, Westin S, Hoffmann A, Subramaniam S, David M, Rosenfeld MG, Glass CK: Molecular determinants of crosstalk between nuclear receptors and toll-like receptors. Cell 2005;122:707-721.

-35 Mangelsdorf DJ, Evans RM: The rxr heterodimers and orphan receptors. Cell 1995;83:841-850.

-36 Mitro N, Godio C, De Fabiani E, Scotti E, Galinozzi A, Gilardi F, Caruso D, Chacon ABV, Crestani M: Insights in the regulation of cholesterol 7 alpha Hydroxylase gene reveal a target for modulating bile acid synthesis. Hepatology 2007;46:885-897.

37 Wagner M, Zollner G, Trauner M: New molecular insights into the mechanisms of cholestasis. J Hepatol 2009;51:565-580. 


\section{Cellular Physiology Cell Physiol Biochem 2018;49:1304-1319 \begin{tabular}{ll|l} 
DOI: 10.1159/000493409 & $\begin{array}{l}\text { O 2018 The Author(s). Published by S. Karger AG, Basel } \\
\text { www.karger.com/cpb }\end{array}$ \\
\hline
\end{tabular} \\ Tong et al.: Omic Study of the Effect of Gentiopicroside on Cholestasis}

-38 Meng Q, Chen XI, Wang CY, Liu Q, Sun HJ, Sun PY, Huo XK, Liu ZH, Yao JH, Liu KX: Alisol B 23-acetate protects against ANIT-induced hepatotoxity and cholestasis, due to FXR-mediated regulation of transporters and enzymes involved in bile acid homeostasis. Toxicol Appl Pharmacol 2015;283:178-186.

39 Bechmann LP, Kocabayoglu P, Sowa JP, Sydor S, Best J, Schlattjan M, Beilfuss A, Schmitt J, Hannivoort RA, Kilicarslan A, Rust C, Berr F, Tschopp O, Gerken G, Friedman SL, Geier A, Canbay A: Free fatty acids repress small heterodimer partner (SHP) activation and adiponectin counteracts bile acid-induced liver injury in superobese patients with nonalcoholic steatohepatitis. Hepatology 2013;57:1394-1406.

-40 Anakk S, Watanabe M, Ochsner SA, McKenna NJ, Finegold MJ, Moore DD: Combined deletion of Fxr and Shp in mice induces Cyp17a1 and results in juvenile onset cholestasis. J Clin Invest 2011;121:86-95.

-41 Minato K, Suzuki M, Nagao H, Suzuki R, Ochiai H: Development of analytical method for simultaneous determination of five rodent unique bile acids in rat plasma using ultra-performance liquid chromatography coupled with time-of-flight mass spectrometry. J Chromatogr B Analyt Technol Biomed Life Sci 2015;1002:399-410.

-42 Lindahl A, Sjoberg A, Bredberg U, Toreson H, Ungell AL, Lennernas H: Regional intestinal absorption and biliary excretion of fluvastatin in the rat: Possible involvement of mrp2. Mol Pharm 2004;1:347-356. 